\title{
A Review of Literature on Parenting Styles, Parental Competence and Emotional Intelligence among College Students
}

\author{
Okoye Chukwuebuka Joseph', Muslihah Hasbullah², Zarinah Arshat ${ }^{3}$, \\ ${ }^{I}$ Master of Science Candidate, Department of Human Development \& . Family Studies, Faculty of Human Ecology, \\ Universiti Putra Malaysia, ${ }^{2}$ Senior Lecturer, Department of Human Development \& Family Studies, Faculty of \\ Human Ecology, Universiti Putra Malaysia, ${ }^{3}$ Associate Professor, Department of Human Development \& Family \\ Studies, Faculty of Human Ecology, Universiti Putra Malaysia
}

\begin{abstract}
Parenting styles and competence predict many aspects of the children's well-being. Studies indicate that parents present the first learning environment for their children before joining schools, and that the impacts they have to their children may influence their children up to college level. Although many studies have been conducted on the impacts of parenting style and parental competence on emotional intelligence, majority of these are mainly in the context of Western or Asian countries and little, or none in the context Nigeria, particularly, in urban area of Anambra State. Therefore, the general objective of the study is to conceptualize the relationships of parenting style and parental competence on emotional intelligence of college students in urban area of Anambra state, Nigeria.
\end{abstract}

Keywords: Parenting styles, Parental competence, Emotional intelligence, Students, Family.

\section{Introduction}

In spite of the massive strides of ${ }^{[1]}$ and other professionals, ${ }^{[2]}$ and $^{[3]}$ among others argued that it is not intelligence quotient (iq) however emotional intelligence that determines one's fulfillment in lifestyles. The person that is high on emotional intelligence is found to be better in managing the conditions of life than person who has low stages of emotional intelligence. Due to this fact emotional intelligence is the potential to understand, apprehend, and manipulate one's emotion; its miles thought to be a vital determinant of a scholar's behavioral disposition. The manner mother and father discipline their children ends in deep and lasting outcomes for the child's emotional life. A harsh remedy has its implication and empathic expertise does too. An

\footnotetext{
Corresponding Author:

Dr. Muslihah Hasbullah

Senior Lecturer, Department of Human Development \& Family Studies, Faculty of Human Ecology, Universiti Putra Malaysia
}

extant literature on how mother and father treat their kids suggests a few mother and father as being indifferent to their kids whilst some display warmth. ${ }^{[3]}$

In line with ${ }^{[4]}$ the connection among affective and emotional elements of parental behavior and the child's emotional adjustment is family and subculture specific. This brings to light the importance of the own family as a good deal studying occurs via interplay between a child and his own family contributors specifically the dad and mom. The family is hence the bedrock for the boom of emotional intelligence.

$\mathrm{As}^{[5]}$ rightly pointed out "own family is our first faculty for emotional learning. A close emotional bonding and good enough conversation between youngsters and parents with clear variations for behaviour can make kids emotionally and socially competent, accountable, and independent and assured". Consequently, emotional intelligence is closely associated with parenting and the age, sex and gender of the children.

Parenting refers to the aspects of raising a toddler and there are several styles often employed by parents to 
raise their children. Parenting style is therefore a mental assembles that is described as well-known techniques used by dad and mom to deliver up their youngsters.

\section{Effects of Parenting Styles on Emotional} Intelligence: Parenting styles have been investigated for many years ${ }^{[6]}$ Some authors have revealed that parenting styles has significant effects on the development of emotional intelligence among the children.

As demonstrated by Baumrind, studies rely on four parenting styles; authoritarian, authoritative, permissive, and uninvolved ${ }^{[7]}$ The typology presented by Baumrind is frequently used by studies because it covers various styles of parenting that range from authoritative (giving more attention) to the neglectful styles (giving less attention to the children). In addition, this typology represents a combination of two child rearing approaches, which include behavioural control and acceptance, which are affected by both temperament of children and parents.

${ }^{[8]}$ examined the relationship between the parenting styles and emotional intelligence, which was developed in two stages. In the first stage, the study examined the mothers' positive or negative parenting styles and their relationships with the emotional intelligence of the children. In the second stage, the study examined the permissive, authoritarian, authoritative, and uninvolved parenting styles, and how they relate to the development of emotional intelligence among the children.

${ }^{[9]}$ conducted a study on the cultural perspectives on the parenting, trait emotional intelligence and mental health. The study findings revealed that there was a positive effects of authoritative parenting styles on the children's mental health is often mediated through the children's trait emotional intelligence. On the other hand, the study found that authoritarian parenting style present a weak relationship with the children's trait emotional intelligence, and that other parenting dimensions become insignificant when other parenting styles are accounted for.

\section{The Types of Parenting Styles:}

Authoritative Parenting Style: According to ${ }^{[10]}$, the qualities of authoritative parenting represent responsive, demanding, supportive, and guidance. In fact, the parents with the authoritative parenting style often show highest levels of support and children to their children ${ }^{[10]}$. Similarly, ${ }^{[11]}$ argue that authoritative parents demonstrate understanding of their children's feelings and often teach them on how to regulate themselves and provide guidance for them to learn from any mistakes they may make as they grow to adulthood. Indeed, they are able to resolve the activities of their children in proper ways and assist them in resolving the problems in their lives. ${ }^{[6]}$ They often demonstrate warmth, are emotionally supportive, and are responsive for their children ${ }^{[12]}$ often encourage open communication in order to enable both parties to be satisfied with each other.

Authoritarian parents also encourage their children to be independent and develop their own identities, however, they also provide boundaries and rules for their children ${ }^{[13]}$. As a result of the guidance provided to the children after their parents set guidance and rules, the children tend to consistently follow them, authoritative parents recognise and set expectations that are appropriate for the children's developmental stages in their lives. Parents are always firm with the rules and offer clear reasons to their children concerning the reasons to follow them, and are open to discussion of particular problems ${ }^{[9]}$ Therefore, there is often a twoway communication that exist between the children and their parents that assists in the development of good child-parent relationship ${ }^{[14]}$ Therefore, it can be argued authoritative parents often treat their children with respect and provide reasons of rewarding or punishing them.

The previous studies indicate that authoritative parenting styles are effective since parents treat their children in warm ways ${ }^{[15]}$. This is because two-way discussion between the children and their parents is helpful in minimizing any problem that may occur. In addition, most studies indicate that well-being outcomes happen children are brought up by authoritative parenting styles ${ }^{[16]}$ These wellbeing outcomes that often happen in families by the authoritative parenting styles may decrease the levels of depression and stress among the children; hence, they are more likely to feel respected, happy, and appreciated by their parents. In this regard, the studies concerning the parenting styles indicate that authoritative parenting styles that combines support and warmth elements is mostly considered to be fulfil the needs of the children development ${ }^{[12]}$ and assist them to develop psychological wellbeing among the children. In this regard, ${ }^{[6]}$ found that there was a positive influence of authoritative parenting styles that exist across ethnicity, gender, socioeconomic status, family structure and time. 
Authoritative parenting style has a positive and significant influence on the development of the children's behaviour and empathy ${ }^{[17]}$. In this regard, ${ }^{[18]}$ reveal that authoritative attributes shown by parents such as monitoring, affection, and stability have a positive impacts children's emotion. Also, one multi-wave longitudinal study examined by ${ }^{[20]}$ on the relationship between authoritative parenting styles, child emotional and development and styles found that these children Who perceive authoritative parenting exhibited higher empathy towards both positive and negative emotions. In another study, ${ }^{[8]}$ examined the children's effortful control and their externalisingbehaviour and found that parenting styles that displayed elements of empathy such as more warmth and less punishment towards their children indicated more effortful control and displayed fewer externalising problems over two or four years later. Therefore, in can be argued that children often learn to feel empathy from their authoritative parents compared to other parenting styles.

Authoritative parenting style has also been found to have minimized the cases of depression symptoms. For instance, ${ }^{[6]}$ examined whether authoritative parenting styles during adulthood relates with young adult depression four years later. The study outcomes revealed that authoritative parenting during childhood is negatively related with young adult depression symptoms. Similarly, ${ }^{[5]}$ found that the children from authoritative parents scored lower on depression in relations with the children that were nurtured using other parenting styles. The authors distinguished between fathering and mothering and its effects on emotional development of children. In this regard, they looked at paternal and maternal parenting and the variations the wellbeing of the children in terms of self-esteem, life satisfaction, and depression. Furthermore, ${ }^{[3]}$ found that authoritative parenting styles reduce the possibility of developing depression among the children. Therefore, in can argued that authoritative parenting styles leads to lower depression among the In other studies, it is revealed that the children nurtured by authoritarian parents are better able to develop social competence. In this regard, when authoritativelynurtured children grow up, they become adults who are ready to adjust within their communities and are aware of what is acceptable ${ }^{[6]}$ In addition, Baumrind found that authoritative parenting style that leads to better adjustment in the community, although the children in the authoritative homes are from an individualistic culture since such authoritative homes receive responsiveness and acceptance from their parents that assist children in the development of social competence. This social competence trend among the children of authoritative parents has been found with children as young as preschool, who have been found to demonstrate higher social competence compared to the children with permissive, authoritarian, and uninvolved parenting styles ${ }^{[21]}$. Once children develop social competence, they become capable of adapting to various adjustments in their lives. In addition, ${ }^{[22]}$ found that supportive and warmth parenting styles were critical in increasing self-esteem and development of positive attitudes among the adolescents. Consequently, by demonstrating greater self-esteem and positive attitude, children have the ability to socially interact with others because they have the confidence to relate with other people.

Overall, children who live with authoritative parents seem to have an advantage in developing their social competence and social adjustment skills compared to children raised under different parenting styles. Also, the study conducted on the parenting styles and the children's behaviours determined that the children with authoritative parents indicated more responsibility unlike the children raised from the families where different parenting styles were used ${ }^{[18]}$. Concerning the academic achievement of the children, ${ }^{[17]}$ suggested that children from authoritative parents showed higher academic achievement, scoring higher on their academic pursuit, particularly, in math and language, unlike children who receive less attention from their parents. Therefore, it can be argued that authoritative parenting styles encourage children to develop a sense of responsibility to themselves and the wider community. Similarly, authoritative parents are able to motivate their children to study hard and achieve higher success in their education.

Authoritarian Parenting Style: The impacts authoritarian parenting styles have also received a lot of attention in literature, especially its impacts emotional intelligence in children. For instance. ${ }^{[13]}$

Who examined the relationship between parenting and delinquency suggested that authoritarian parents showed low responsiveness and warmth, but demonstrated high control over their children. Authors argue that authoritarian parenting style attempt to control, shape, and evaluate the attitude and behaviour of their children in accordance to a set of principals they 
offer. These parents tend to be strict and conservative in nature. In this regard, children are offered with little choice and are often expected to orders provided by their parents ${ }^{[17]}$. Also, these parents are considered to be having expectations, and their children are not expected to disobey their parents at any given time.

${ }^{[13]}$ describes authoritarian parents as those who often monitor the behaviour of their children. Similarly, ${ }^{[2]}$ described it as "parents attempt to manage or control children's behaviour" (p. 3296). Barber further determined behavioural control as the act of the parents' monitoring their children's activities and behavioural outside the home. For instance, these parents always want to know where their children are and what they might be doing. In addition, as part of parental control, such parents also get involved in decision-making for their children. In this regard, children do not have the opportunity to make a decision on what they want; hence become less self-confident in their lives ${ }^{[8]}$

The relationship between authoritarian parenting style and the children's life satisfaction has also been examined in the previous studies. For instance, in a study conducted by [21], it was revealed that the children's life satisfaction decreased when they were nurtured by authoritarian parenting fathers. In addition, ${ }^{[22]}$ indicated that the element of punitive and control nature of the authoritarian parenting may make the children to feel dissatisfied and unhappy with their lives. Therefore, it can be argued that authoritarian parenting styles may lead to minimal life satisfaction among the children.

Overall, authoritative parenting styles present less desired effects on children than authoritative parenting. This parenting style has been found to increase depression, as well as delinquency among the adolescents and children. Also, evidence from the studies reviewed indicate that authoritarian parenting leads to lower selfesteem and life satisfaction among the children and limit the ability of the children to think and make their own decisions. The practice of authoritarian parenting of ignoring the significance of considering the thoughts of children may lead to depression among the children. In addition, the children nurtured by authoritarian parenting often develop less responsibility since their parents make their decisions for them to follow, hence the children only depend on the parents in almost everything. Therefore, since authoritarian parenting is demanding, harsh, and strict, the children from these families often develop delinquent behaviour.
Permissive Parenting Style: Permissive parenting style has also reported significant impacts on the development emotional intelligence. For example, according to ${ }^{[6]}$ permissive parents present non-punitive, affirmative, and acceptance behaviour towards the need's actions and desires of the children. Studies have reported negative and positive elements of permissive parenting on emotional intelligence. For instance, [24] indicated that permissive parenting styles present greater support and responsiveness for their children, whereas at the same time presenting little or low control over their children. Also, ${ }^{[25]}$ emphasized that permissive parents are more liberal and offer full autonomy to their children and support whatever the children like doing. These parents are accepting and nurturing in nature and are also responsive to the wishes and needs of their children. Also, permissive parents encourage their children to do what they like doing.

[20] present that permissive parents provide their children with freedom to act without setting limits and monitoring. In this regard, these parents hope that by providing their children with freedom, the relationship with their children would become stronger ${ }^{[21]}$ Therefore, the children nurtured by permissive parents often regulate and plan their own activities at a younger age without much parental attention. Similarly, ${ }^{[7]}$ stated that since the children the children of the permissive parents always independently do their activities, these children are perceived to be more responsive and mature. ${ }^{[5]}$ also insisted that while parents with permissive parenting style are considered to be responsive to their children, they often fail in setting boundaries and expectations for their children. However, it has been reported that permissive parenting style id considered to be potentially unsafe for their children because it is unsuccessful in the development of good judgement among their Children authoritative mothers. On the other hand, ${ }^{[6]}$ argued that permissive parents presented both negative and positive impacts on the children's emotional intelligence. Besides, ${ }^{[7]}$ argued that permissive parents are more supportive of what their children want to be done and the attitude led to lower depression among the children. In contrary to these findings, ${ }^{[19]}$ indicated that permissive parenting leads to depression among the children because when their parents are too lenient and allow their children to what the children wish to do, the children lack the focus and might end up doing something inappropriate. Therefore, it can be argued that permissive parenting is appropriate and may result into more problematic behaviours among the children. 
Overall, it can be argued that permissive parenting styles contribute to antisocial and depression behaviour among the children. In this case, parents with permissive parenting style are too tolerant and lenient of their children's actions without necessarily setting limits. Consequently, this situation may lead to children lacking the ability to differentiate between what is bad and good for them. They are often inconsistent and relaxed in the provision of feedback to their children, which may lead to the situation where the children feel confused with regards to what is good and bad for them. Also, in permissive families, children often think that they can do what they want to do and do not learn to respect anything. Therefore, the literature review presented in this section alludes to the fact that permissive parenting style may not be appropriate in the development of the children's emotional intelligence children

Uninvolved Parenting Style: Uninvolved parenting styles have been reported in literature as a common phenomenon, leading to significant impact on the development of emotional intelligence. For instance, [23] carried out a meta-analysis on the relationship between parenting style and delinquency. The study findings revealed that uninvolved parenting style represent the parents who presented low control and low support for their children. In fact, they show low control, low responsiveness and warmth to their children, and pay less attention and offer little or no care ${ }^{[24]}$ According to the authors, these parents may appear to be disconnected, low on sensitivity, undemanding, and not often set limits for their children. They also do not pay any attention to the opinion and emotions of their children. However, such parents may be emotionally unsupportive for their children, but may still provide their children with basic needs like shelter and food. As a result, the children being nurtured by uninvolved parents pay feel that some aspects of their parents' lives are more important than they actually are. According to ${ }^{[25]}$, the parents with uninvolved parenting styles demonstrate detached behaviours towards their children; hence the children may feel disengaged when their parents were uninvolved and spend less time with them

Overall, uninvolved parenting style present negative impacts on life satisfaction, depression, aggression, delinquency, antisocial behaviour, and attitudes. It can be argued that uninvolved parenting style mostly appears to worsen the psychological development of the children, even though such children may show good relationship with their peers. Moreover, the children who are nurtured by uninvolved parenting style may often develop low self-esteem and depression. In this regard, they may think that their parents do not actually care about them; hence they are free to do what they desire. Also, they may think that their parents have no or little monitoring on their behaviour. Therefore, it can be argued that uninvolved parenting styles may disadvantage the children's ability to develop emotional intelligence, which may lead to the development of antisocial behaviour and aggression among the children.

Effects of Parental Competency on Emotional Intelligence: Parenting involves numerous parenting activities, behaviours, and duties that are directed towards protection, care, child rearing and nurturing ${ }^{[26]}$ This refers to a feeling that can be simultaneously stressful and satisfying in nature. In this regard, the feeling of satisfaction often depends on the level at which a parent is satisfied with their relationship with children and their own parental role [27]. it can be described as a feeling of affinity for a particular role, reward, and fulfilment, rather than a feeling of dissatisfaction that is attributed by a sense of manipulation, imposition of excessive control, as well as frustration. The levels of satisfaction often depend on the parental assessment of the behaviour of the children. In this case, when a parent estimates that the changes in the development of the children are consistent with their relationships with their children, parental satisfaction is higher; hence indicating the extent of parental competency ${ }^{[28]}$ Conversely, a feeling of stress and dissatisfaction can have negative impacts on the parental role, which may ultimately reflect on the development of the circumstances of hindrances within the family environment ${ }^{[28]}$. This dissatisfaction by the parental role significantly influences the reduced parental competency, whereas higher satisfaction may positively affect the experience of the parental competence.

Parental competence can be described as an experience of an individual's own ability to resolve the day-to-day challenges in the child nurturing The assessment of parental competence can be done through measuring the degree at which the parent feels confident in their own parental role. In this regard, parents who feel that they are confident in their own behaviour and trust, their abilities are often more motivated in meeting the expectations. In order to experience control over the challenges of parenting, it is imperative that parents set realistic child development excitations. 


\section{Conclusion}

Competency-based approaches are increasingly perceived as a central strategy for the improvement of effective care and enhance the development of emotional intelligence we can argue that parenting is an act of providing for and supporting the intellectual, emotional, physical, as well as social development of the children from infancy to adulthood. The author further proposes that parenting competence is a learned ability geared towards effectively nurturing children by performing the required tasks through demonstrable skills, knowledge or abilities, behaviours or practices, attitudes, attributes, and clusters of these elements associated with the positive outcomes in children.

Ethical Clearance: Taken from Universiti Putra Malaysia Ethics Committee (JKEUPM).

Ref no- JKEUPM-2020-370.

Source of Funding: Self

Conflict of Interest: Nil

\section{Reference}

1. Barnhart, P. C. Building strong relationships in families. Hand book of good parenting : vol.6 clinical counseling and behavioral science (4th ed). Washington DC. . (2013). p. 200-240

2. Bar-On, R. E., \& Parker, J. D. The handbook of emotional intelligence: theory, development, assessment, and application at home, school, and in the workplace. Jossey-Bass. (2000). p. 146-156

3. Goleman, D. Working with. Emotional intelligence. Bantam. (1998). p. 150-160

4. Obiunu, J. Influence of parenting styles on the academic performance of college students in Ethiope east local Government Area, Delta State. International Journal of Educational Technology and Learning, (2018). p.54-58

5. Goleman, D. An EI-based theory of performance. The emotionally intelligent workplace: How to select for, measure, and improve emotional intelligence in individuals, groups, and organizations. (2001). vol 1, p. $27-44$

6. Goleman, D. Emotional intelligence. New York, NY, England. (1995).p. 56- 70

7. Emagnaw, A. B., \& Hong, J.-z. .Relationship among Parenting Styles, Prosocial Behavior and
School Performance of Students Who are Attending to Grade Seven and Eight State Schools. American Journal of Educational Research and Reviews. (2018)

8. Baumrind, T. The influence of parenting style on adolescents competence and subctance. Journal of Early Adolescence, (1988) p. 24-31

9. Hoffman, M. L. Power assertion by the parent and its impact on the child. Child Development, (1960). P. 29-143

10. Hong, E. Impacts of parenting on children's schooling. Journal of Student Engagement: Education matters, (2012). p. 31-41

11. Husain, T. Adolescents trouble with parents. Pakistan: Talimir Press. (2006)

12. Ibukunole, C. Payer and service to specific estimates. Health affairs"' Journal,(2013). p. 31-72

13. Kumar, R. Research methodology: A step-by-step guide for beginners.London : SAGE.(2014)

14. Salovey, P., \& Mayer, J. D. Emotional intelligence. Imagination, cognition and personality(1990)., 9(3), p. 185-211

15. Maccoby, E. E., \& Martin, J. Socialization in the context of the family: Parent child interaction. In R H. Mussen (Series Ed.) \& E. M. Hetherington (Vol. Ed.). Handbook of Parenting Styles 32 child psychology: Vol. \$. Socialization, personality, and social development.(1983)

16. Nwagwu, J. Gender Difference in Adolescents Perception of Parental Acceptance/Reflection. Nigeria Journal of Clinical and Counselling Psychology, (1995). p.110- 119.

17. Obiunu, J. Influence of parenting styles on the academic performance of college students in Ethiope east local Government Area, Delta State. International Journal of Educational Technology and Learning, (2018). p.54-58.

18. Odongo, A. A., Aloka, D. P., \& Raburu, D. P. Influence of parenting styles on the adolescent students' academic achievement in Kenyan day college schools. Journal of Education and Practice. (2016)

19. Okoro, G. Influence of parenting styles on adolescent's delinquency in Delta Central senatorial Sub County. Edo Journal of Counseling,(2013). p. 39-42.

20. Osorio, A., \& Gonzalez-Camara, M. Testing the 
alleged superiority of the indulgent parenting style among Spanish adolescents. Psicothema (2016).p., 414-420.

21. Maphoso, \& Dikeledi, M. The Influence of Parental Involvement on academic achievement in boarding and Non-Boarding schools. Mediterranean Journal of Social Sciences, (2014). p.155-165.

22. Mayer, J. D., Salovey, P., \& Caruso, D. R. Models of emotional intelligence. RJ Sternberg (ed.).(2000).

23. Mayer, J. D., Salovey, P. Emotional development and emotional intelligence: Implications for educators. What is emotional intelligence, (1997).

24. Mau, W., Hitchcock, R., \& Calvert, C. High school students' career plans: The influence of others' expectations. Journal of Professional School Counseling.(1998).

25] Moore, O. Influence of parental involvement on the academic achievement of adolescents,
Paper Presented at the Annual Conference of the American Psychological Association. Washington D.C: Wiley.(2011).

26] Pinquart, M. Assiociations of parenting styles and dimensions with academic achievement in childern and adolescents: A meta-analysis. Educational Psychology Review. (2016)

27] Pinquart, M., \& Kauser, R. Do the associations of parenting style with behavior problems and academic achievement vary by culture? Results from a meta-analysis.Culture Divers Ethnic Minor Psychol. (2018). p.75-100.

28. Steinberg, L., Elimen, J., \& Mount, S. Authoritative Parenting psychosocial maturity and academic success among adolescents. Child Development, (1989). p.1424-1436. 